\title{
A Importância de Políticas Públicas Além da Escola Formal para o Desenvolvimento Infantil e Adolescente: Uma revisão de literatura ${ }^{1}$
}

\author{
Neyfsom Carlos Fernandes Matias \\ Universidade Federal de Minas Gerais
}

\begin{abstract}
RESUMO
O que crianças e adolescentes fazem fora da escola ou como utilizam o seu tempo livre tem sido objeto de estudo para diversos pesquisadores. Estes têm destacado a necessidade de levantar dados sobre estas atividades e como as mesmas podem influenciar diferentes aspectos, tais como: desempenho acadêmico, desenvolvimento físico, cognitivo e de habilidades sociais, entre outros; além de conjugar duas variáveis importantes à infância e à adolescência: a proteção social e a educação. Neste sentido, este artigo apresenta questões envolvidas em atividades extracurriculares para crianças e adolescentes, denominadas de ações socioeducativas no Brasil. Trata-se de um estudo de revisão da literatura que apresenta a importância das atividades extracurriculares, quais os principais impactos destas ações aos seus participantes apresentados em pesquisas realizadas por diversos investigadores. As considerações apontam a necessidade da realização de estudos empíricos sobre o tema no Brasil, a fim de detectar se os dados elencados pela literatura internacional se fazem presentes no país. Além disso, informações dessa natureza poderão ser úteis para planejar e executar políticas públicas para crianças e adolescentes fora do contexto educacional ou para a ampliação da jornada escolar e implantação de escolas de tempo integral que fomentem impactos positivos na aprendizagem de estudantes das escolas brasileiras.
\end{abstract}

Palavras-chave: atividades extracurriculares; crianças; adolescentes; políticas públicas.

\section{ABSTRACT \\ The Importance of Public Policy out of the Formal School in Childhood and Adolescence Development: A literature review}

What children and adolescents do outside of school or how they use their free time has been an object of a number of studies. These have highlighted the necessity of gathering data about these activities and how they can influence: academic performance, physical, cognitive and social abilities development, among others. Besides, they unite two important variables to childhood and adolescence which are the social protection and education. Therefore, this article presents some questions involved in extracurricular activities for children and adolescents named, in Brazil, "ações socioeducativas" (socio-educative actions/programs). This literature review shows the importance of extracurricular activities and what the main impacts of these programs are to its participants through surveys conducted by different investigators. The considerations of this article point to the necessity of doing empirical studies about this theme in Brazil, in order to detect if the data highlighted by the international literature are representative in this country. In addition to this, this kind of information can be useful when planning and executing public policies for children and adolescents outside of the educational context or by the extension of school hours and the implementation of full time schools that develop positive aspects in the students' learning at the Brazilian schools.

Keywords: extracurricular activities; children; adolescents; public policy.

A política pública é uma expressão de decisões de pessoas que estão ocupando posições definidas no governo, uma ação localizada em instituições específicas, lugares que possuem ou dão a prerrogativa a quem os ocupa de realizar determinadas atuações. É uma esfera de atuação institucionalizada que pode resultar em demandas dos governados ou em ação do governante que, através do resultado de uma pesquisa, por exemplo, pense que é necessária a entrada do governo em uma área na solução de problemas que afetam a vida das pessoas (Souza, 2003). Nem toda política pública se caracteriza necessariamente como obrigatória, apesar de dizer respeito "à alocação imperativa de valores pelo Estado para a sociedade" 
(Siman, 2005, p.29). Ela tem o intuito de realizar determinados fins que foram decididos por aqueles que detêm o poder de gestão das ações nos governos, seja no âmbito Federal, Estadual ou Municipal, e pode ser elaborada a partir da demanda da sociedade ou por decisões de grupos específicos que têm a função de desenvolver atuações públicas (Zauli, 2003).

A execução de políticas públicas envolve profissionais de distintas áreas, como Psicologia, Medicina, Serviço Social, dentre outras. A Psicologia está presente em inúmeras ações de governo como, por exemplo, nas políticas públicas de Saúde, Assistência Social, Educação. Este artigo de revisão da literatura diz respeito à contribuição desta área na elaboração de políticas públicas voltadas para o atendimento de crianças e adolescentes, em atividades no contraturno escolar, bem como na necessidade da educação de tempo integral. Mais precisamente procura-se apontar, a partir da literatura que trata de questões envolvidas em atividades extracurriculares, que a prática e execução de programas fora do âmbito escolar se justificam por promover uma formação integral para a vida de quem participa deles.

O objetivo deste artigo, de uma maneira geral, não é de contrapor a importância que tais programas possuem no sentido de proporcionar um lugar para crianças e adolescentes ficarem e não se exporem a vulnerabilidades, nem no quesito da participação obrigatória pelo recebimento de benefícios de bolsas ligadas a programas que visam, por exemplo, a eliminação de trabalho infantil doméstico (Circo de Todo Mundo, 2004). A ideia é demonstrar a necessidade de ações extracurriculares como espaços que contribuam para o desenvolvimento, como um todo, dos seus participantes a partir de estudos que investigaram os efeitos das atividades extracurriculares (Centro de Estudos e Pesquisas em Educação, Cultura e Ação Comunitária, 2002).

Huston (2005) aponta que alguns policymakers ${ }^{2}$ têm se tornado mais conscientes da necessidade do conhecimento desenvolvido em pesquisas, objetivando o desenho de políticas sólidas e efetivas. Em sintonia com esta autora, defende-se na presente oportunidade a ideia de que é de suma importância que a política pública, no seu processo de elaboração e execução, esteja lado a lado com o conhecimento produzido por diversas áreas, para que seja possível uma ação profícua. Apresentar os impactos das atividades extracurriculares pode contribuir tanto para o fortalecimento das mesmas, como para o planejamento de políticas públicas sólidas dedicadas à infância e à adolescência no
Brasil, bem como fornecer subsídios para a realização de pesquisas empíricas sobre o tema (Matias \& Souza, 2007a).

Este trabalho é resultado de indagações que passam pelas possíveis contribuições que a Psicologia pode oferecer à elaboração e execução de políticas públicas para crianças e adolescentes. A ideia é de que as considerações levantadas sejam úteis àqueles que possuem interesses concernentes às ações voltadas à infância e à adolescência no contraturno escolar. A investigação sobre as variáveis envolvidas em programas extracurriculares para a escola brasileira ainda é embrionária. Apesar disso, existem experiências que visam ao atendimento de crianças e adolescentes em horários alternados ao da escola. É possível observar que estas iniciativas têm surgido como propostas pontuais atreladas a programas, em sua maioria, de cunho social. No entanto, os impactos que as mesmas possuem para os participantes têm tido pouca atenção de pesquisadores brasileiros (Matias, 2009). Como exemplo destas ações, pode-se destacar a "Jornada Ampliada" do Programa de Erradicação do Trabalho Infantil (Pontifícia Universidade Católica de Minas Gerais, 2007), atrelada ao Governo de Minas Gerais. Há um considerável número de ações sociais desenvolvidas por organizações não governamentais (ONGs) que atendem o público infanto-juvenil no contraturno escolar (Circo de Todo Mundo, 2004). Muitas destas ações, como a referida anteriormente, possuem uma atuação significativa. No entanto, algumas, devido ao seu caráter pontual, não têm sido permanentes. Portanto, cabe destacar também a necessidade de que estas ações tenham caráter contínuo, como parte de uma política pública de fato ou de que escolas de tempo integral sejam uma realidade no Brasil.

\section{MÉTODO}

Foi realizado um levantamento de publicações sobre atividades extracurriculares em quatro periódicos brasileiros de Psicologia nos respectivos períodos: Psicologia: Reflexão e Crítica (de 1987 a 2006); Psicologia: Teoria e Pesquisa (de 1985 até 2006); Psicologia: Ciência e Profissão (de 1997 até 2006); Psicologia Escolar e Educacional (de 1996 até 2006). A escolha por estas revistas foi em função de que elas possuem repercussão nacional e, com exceção da $P s i-$ cologia Escolar e Educacional, publicam estudos das mais distintas áreas psicológicas, tanto trabalhos de cunho científico como profissional.

Foram traçados os seguintes critérios para a seleção de textos que seriam analisados e fariam parte da 
amostra: todos os que possuíssem palavras-chave nos títulos como programas extracurriculares, oficina(s) (por ser um termo que pode designar trabalhos não acadêmicos), contraturno, extraescolar, atividade(s) extracurricular(s), projeto(s), ação socioeducativa. Para o destaque destes termos, levou-se em consideração terminologias que pudessem remeter a atividades realizadas fora do período e ambiente escolar.

A partir da detecção de um dos termos levantados no título dos trabalhos fez-se uma leitura do resumo. Caso houvesse relação ou destaque referente a atividades extracurriculares, o texto seria selecionado para compor a revisão. Contudo, não foram localizadas publicações que tratassem de atividades extracurriculares nos periódicos investigados. O que destacou a informação de que não havia pesquisas sobre o tema nas revistas pesquisadas e da necessidade de pesquisas nesta área no Brasil.

Diante do fato de não haver estudos nos periódicos brasileiros, optou-se pela realização de uma pesquisa na base de dados PsycINFO, no dia 21/06/2007 a partir da palavra "extracurricular". A escolha por este termo foi em função de haver uma frequência do mesmo em trabalhos que tratam de atividades realizadas fora da instituição escolar no período que antecede e sucede o tempo na escola. Foram selecionadas somente publicações em que o termo "extracurricular" aparecesse no título. O produto desta pesquisa foi de 177 trabalhos. Destes 111 foram artigos em periódicos, 59 teses (dissertations) e 07 livros ou capítulos de livros, publicados entre 1927 e 2007. A ideia original era a de realizar uma análise do conteúdo de todos os resumos encontrados ${ }^{3}$. Contudo, a fim de possibilitar uma discussão aprofundada e devido ao fato de não ter sido encontrados estudos sobre o tema nos periódicos brasileiros, para a presente revisão considerou-se duas questões para a seleção dos trabalhos: (1) necessidade de apresentar o tema de forma consistente e com maiores informações, o que não seria possível somente a partir da leitura dos resumos; (2) entre os textos levantados na base de dados PsycINFO, fizeram parte desta revisão todos aqueles que já haviam sido consultados integralmente e encontrados em pesquisas exploratórias em periódicos internacionais como Child Development, Journal of Educational Psychology, Review of Educational Research, Developmental Psychology, dentre outros; e livros que tratam de atendimento para crianças e adolescentes no contraturno escolar publicados no Brasil.

A partir destes critérios a leitura dos trabalhos teve os seguintes objetivos: destacar a importância de atividades extracurriculares para o desenvolvimento infantil e adolescente, definir o que são estas atividades, quais os principais impactos destas ações aos seus participantes apresentados por estudos empíricos. Ao todo foram selecionados 24 trabalhos para a revisão, 20 retirados de periódicos e 4 livros cujo conteúdo é apresentado nas duas próximas seções.

\section{A importância das atividades extracurriculares para o desenvolvimento da criança e do adolescente}

Com a expansão do mercado de trabalho, observa-se um movimento crescente de mães que se inserem em atividades laborais, que inviabilizam o tradicional cuidado com os filhos fora do período escolar. Este movimento cria uma demanda para a implantação de programas que cuidem dessas crianças e adolescentes quando não estão na escola (Sherrod, 2006). Na ausência de tais propostas, este público estará exposto a riscos e acidentes, na permanência em casa, sem a supervisão de um adulto e a situações de vulnerabilidades, como, por exemplo, trabalho infantil, aliciamento para o tráfico de drogas ou vitimização pela violência direta.

Na avaliação de Poletto, Wagner e Koller (2004), há ainda outro risco comum associado à ausência de monitoramento parental no desenvolvimento infantil e adolescente. Para as autoras,

famílias com baixo nível sócio-econômico, com pais desempregados ou empregados em profissões de status (grifo das autoras) baixo, famílias numerosas e ausência de um dos pais podem exigir que irmãos mais velhos tenham que tomar conta dos mais novos para que ambos os pais possam lutar pela sobrevivência do grupo (Poletto \& cols., 2004, p.243).

Estes casos demonstram a importância de ações complementares à escola, que podem ser uma alternativa ao cuidado de parte da família sob a responsabilidade de irmãos mais velhos, como apresentado no estudo de Poletto e cols. (2004).

Há uma concordância generalizada de que a ausência da criança na rua ou em casa sem a supervisão adulta justifica a implantação e a execução de programas no contraturno escolar ou de escolas de tempo integral. No entanto, estes espaços devem fomentar uma formação integral para a vida de quem participa deles, com a aprendizagem acontecendo em vários espaços de forma efetiva (Centro de Estudos e Pesquisas em Educação, Cultura e Ação Comunitária, 2003), não sendo apenas um lugar para manter crianças e adolescentes seguros; é preciso mais do que isso 
(Centro de Estudos e Pesquisas em Educação, Cultura e Ação Comunitária, 2002).

Cooper, Valentine, Nye e Lindsay (1999) apontam que as características dos estudantes, dos contextos que frequentam e o modo como preenchem o tempo fora da escola são fatores que impulsionam o desenvolvimento das aprendizagens que ocorrem no espaço escolar. O que crianças e adolescentes fazem após ou antes da escola tem sido objeto de estudo de diversos autores (Eccles, Stone \& Hunt, 2003; Eccles \& Taempleton, 2002; Hansen, Larson \& Dworkin, 2003; Mahoney, 2000; Mahoney, Harris \& Eccles, 2006).

$\mathrm{O}$ conhecimento das condições que afetam o desenvolvimento deste público em diferentes contextos contribui para a criação de ações públicas eficazes (Huston, 2005). Assim, faz-se necessário a busca por embasamentos empíricos que possam ser utilizados como fontes de consulta para a implantação e execução de políticas públicas voltadas à criança e ao adolescente no Brasil, a fim de destacar o que pode influenciar ou não este público diretamente.

As atividades extracurriculares são programas desenvolvidos antes ou após o horário escolar, destinadas a crianças, adolescentes e até mesmo jovens adultos, com faixa etária de 5 a 24 anos. Este público participa de atividades desenvolvidas por programas estruturados, fora do espaço escolar e de suas casas, sob supervisão adulta, durante o tempo em que muitos pais estão trabalhando. São programas que oferecem oportunidades de assistência acadêmica, recreação e aprendizagens enriquecidas (Mahoney \& cols., 2006), envolvendo encontros regulares em contextos específicos como salas de aula, quadras, ginásios, auditórios e salas de música (Mahoney, Cairns \& Farmer, 2003).

Carvalho e Azevedo (2005), ao falarem sobre atividades realizadas fora da escola no Brasil, as definem como ações socioeducativas. As autoras destacam que há uma série de denominações utilizadas por crianças, famílias, educadores e organizações, tais como: Projeto, Ação Complementar, Contraturno Escolar, Núcleo, Jornada Ampliada, Espaço Gente Jovem, Clube da Turma, Contraturno Social, Centro da Juventude, PIÁ, Núcleos Socioeducativos. Na concepção de Carvalho e Azevedo (2005), ações socioeducativas são ações que conjugam educação e proteção social, isto é, duas dimensões da proteção integral à infância e à juventude. São atividades que atendem crianças, adolescentes e jovens no período alternado ao escolar que, junto com o processo de escolarização, investem no desenvolvimento integral das crianças e dos jovens que fazem da educação para o convívio em sociedade e para o exercício da cidadania uma estratégia de proteção à infância e à juventude.

Atualmente, as ações socioeducativas são avaliadas para que sejam inseridas no âmbito da política pública no Brasil. Há, sobretudo, uma necessidade de se discutir o sentido destas ações que produzem

oportunidades de aprendizagem sem ser repetição do espaço escolar. Não possui um currículo e uma programação pedagógica padrão. Ao contrário, sua eficácia educacional está apoiada num currículo-projeto que nasce das demandas, interesses, particularidades e potencialidades da comunidade e por sua própria iniciativa. (...) Garante proteção social (...) (que) é política pública necessária a (...) cidadãos desprotegidos porque não estão incluídos e usufruem precariamente dos serviços das políticas básicas (saúde, educação, habitação). Estão desprotegidos porque estão fora das malhas de proteção alcançadas pela via do trabalho, ou estão fora porque perderam relações e vínculos sociofamiliares que asseguram pertencimento. (Carvalho \& Azevedo, 2005, p.28)

Destaca-se que o foco das ações socioeducativas não se limita a questões que perpassam a situação social dos envolvidos. Estas atividades impactam, em certa medida, sobre o seu processo de desenvolvimento de forma integral. A partir disso, vê-se a necessidade de se investigar de que maneira isso acontece, quais são os impactos das ações fora da escola sobre o desenvolvimento infantil e adolescente e em que âmbito isso se destaca. A premissa é de que estes programas possam atingir a todos, independentemente do estrato social. É lícito considerar que os mais necessitados precisam do atendimento das ações socioeducativas. Eccles e cols. (2003) destacam que as atividades extracurriculares são especialmente importantes para jovens que vivem em comunidades pobres. No entanto, as atividades devem se justificar pelo efeito no desenvolvimento daqueles que estão inseridos nestas e não somente por questões sociais e econômicas (Centro de Estudos e Pesquisas em Educação, Cultura e Ação Comunitária, 2002).

Além dos programas extracurriculares ou ações socioeducativas, as atividades extraescolares informais realizadas por crianças e adolescentes, como lazer, assistir televisão, praticar esportes, cuidar de irmãos menores e fazer o dever de casa, têm sido objeto de muitas pesquisas (Coley, Morris \& Hernandez, 2004; Cooper \& cols, 1999; Ferreira \& Mettel, 1999; National Institute of Child Health and Human Development Early Child Care Research Network, 2004; Posner \& Vandell, 1999). Estas investigações procuram conhe- 
cer como e onde as crianças e adolescentes utilizam seu tempo livre fora da escola, e como estas atividades interferem em suas habilidades sociais, nos relacionamentos ao logo da vida, nas atitudes e comportamentos com outras pessoas e até mesmo no desenvolvimento escolar (Eccles \& cols., 2003; Huston, Wright, Marquis \& Green, 1999; Mahoney \& Cairns, 1997; Mchale, Crouter \& Tucker, 2001; Poletto \& cols., 2004).

A investigação sobre os impactos das atividades fora da escola e os programas extracurriculares no desenvolvimento humano é incipiente no Brasil (Matias, 2009; Matias \& Souza, 2007b). Isto estimula a busca por estudos conduzidos em outros países, com vistas ao levantamento de modelos para embasar as investigações brasileiras. Com exceção dos estudos de Carneiro e Dodge (2007), Carvalho e Azevedo (2005), Centro de Estudos e Pesquisas em Educação, Cultura e Ação Comunitária (2002 e 2003), Ferreira e Mettel (1999), Matias (2009), Poletto e cols. (2004), citadas neste trabalho, que trazem dados sobre as atividades extracurriculares, todos os outros são estudos norte-americanos. É preciso considerar as diferentes culturas, sendo as investigações realizadas fora do Brasil potencialmente úteis para levantar questões para pesquisas futuras no contexto brasileiro (Matias, 2007b).

Estudos conduzidos recentemente e publicados em periódicos internacionais apontam que crianças e adolescentes que frequentam atividades extracurriculares apresentam ganhos significativos no desenvolvimento cognitivo, nas atividades acadêmicas (Mahoney, Lord \& Carryl, 2005), e também nas relações interpessoais (Cooper \& cols., 1999; Eccles \& Taempleton, 2002). Estas investigações são fontes fundamentais para pesquisas sobre atividades extracurriculares.

Mahoney e cols. (2006) afirmam que a participação em atividades organizadas após o período escolar traz consequências positivas em atividades escolares, educacionais, sociais, cívicas e no desenvolvimento físico dos participantes. Os autores destacam ainda que crianças participantes de programas extracurriculares podem ter melhor desempenho em leitura com relação àquelas que não realizam tais ações (Mahoney $\&$ cols., 2005). Além disso, participar de uma atividade estruturada, fora da escola, pode proporcionar um aumento de boas interações com parceiros sem comportamentos agressivos, na ampliação deste tipo de relação, bem como contribuir na construção de planos positivos para o futuro (Mahoney \& cols., 2003).

Programas extracurriculares organizados com encontros regulares, conduzidos por um adulto competente, contendo atividades com objetivos claros, podem surtir efeitos positivos a seus participantes (Mahoney, 2000). Pode-se entender, a propósito, que o adulto competente deva ser identificado por um educador qualificado ou por um profissional treinado e que tenha em mente os efeitos que estas ações podem causar. Como exemplo destes profissionais, destacam-se professores com formação em Magistério, educadores sociais ou comunitários comuns em projetos sociais (Pontifícia Universidade Católica de Minas Gerais, 2006), dentre outros.

Na avaliação de Posner e Vandell (1999), é possível detectar efeitos positivos de programas extracurriculares planejados, envolvendo música e dança, por exemplo. Segundo os autores, as crianças que participam de atividades enriquecedoras possuem melhores relações com os colegas e melhor ajustamento emocional na escola em relação àquelas que utilizam menos tempo nestas atividades. Estas crianças apresentam algumas posturas diferentes: assistem menos televisão, não brincam fora de casa em atividades não estruturadas e não são submetidas a trabalhos domésticos. Elas utilizam mais tempo em aulas de dança, teatro e atividades academicamente orientadas (Posner \& Vandell, 1999).

A Lei de Diretrizes e Bases para a Educação (LDB) (Brasil, 1996) aponta que os processos formativos se desenvolvem, entre outros contextos, na convivência humana. Acredita-se que a elaboração de programas extracurriculares, de caráter não escolarizante, pode contribuir na formação de sujeitos com abrangência para além do âmbito acadêmico. Esta formação pode ter como base real a convivência humana, desde que se busque uma configuração que conjugue esforços para tal empreendimento. Ou seja, a lei reconhece e valoriza iniciativas desenvolvidas para além da escola, como, por exemplo, de ONGs em parceria com a escola (Guará, 2003; 2007). A convivência ressaltada na LDB (Brasil, 1996) abrange todos os espaços que as crianças e adolescentes ocupam ao longo de seu desenvolvimento. Com isto, pensar nestes contextos para o desenvolvimento da educação em tempo integral possibilita a elaboração de ações neste sentido. A própria LDB destaca a necessidade de se conjugar todos os esforços para que crianças e adolescentes fiquem mais tempo na escola ou em atividades de educação (Brasil, 1996).

Carneiro e Dodge (2007, p. 21), em uma pesquisa denominada "A descoberta do brincar", realizada em todo o Brasil, com o objetivo de "mapear o brincar (grifo das autoras) da criança brasileira e explorar, mais especificamente, as relações existentes entre a brincadeira e o desempenho escolar", apontam que 
97\% das crianças que participaram do estudo têm como brincadeira principal assistir TV/vídeos/DVD em casa. Destes, 96\% realizam esta brincadeira "mais de três vezes por semana" (Carneiro \& Dodge, 2007, p. 208). Huston e cols. (1999) destacam que tal atividade pode exercer uma influência negativa sobre estes espectadores, comprometendo, por exemplo, a leitura de livros, atividades de lazer e interação com os pais. No estudo de Carneiro e Dodge (2007, p. 206), 84\% dos pais das crianças participantes da pesquisa responderam que tal atividade é boa para seus filhos. Huston e cols. (1999) apontam que "crianças que possuem talento ou habilidade em leitura, esportes, atividades sociais, que têm oportunidades de brincar fora com seus colegas, ou participar de outras atividades similares, podem assistir pouca televisão como consequência" (p. 914).

É importante, destacar estes dados para contrastar com aqueles relatados em publicações que tratam de características que norteiam e influenciam o desenvolvimento humano. Assistir televisão, por exemplo, pode surtir efeito no desenvolvimento de crianças e adolescentes. Sendo esta uma atividade que não proporciona interação e que coloca as pessoas apenas como espectadoras sem exigir esforços, esta ação não impulsiona habilidades essenciais como interagir com colegas, desenvolver a leitura, usufruir de um desenvolvimento físico saudável com a prática de esportes, dentre outras.

Considerando que na investigação de Carneiro e Dodge (2007) 97\% das crianças brasileiras, entre 6 e 12 anos, assistem TV/vídeos/DVDs em casa como brincadeira, é de extrema relevância investigar a implicação desse elevado contato com a mídia televisiva ao desenvolvimento infantil e adolescente. Precisamente, é necessário atentar para o que as crianças e adolescentes fazem além das atividades básicas, como ir à escola, ficar em casa ou estar próximos aos pais, e as implicações dessas ações em seu desenvolvimento global no contexto brasileiro.

Pelo exposto, destaca-se que é urgente a realização de estudos, no Brasil, que abarquem as atividades que são majoritariamente realizadas fora do ambiente escolar, relacionando-as com questões relativas ao desempenho escolar, interpessoal e familiar, além da interseção com a violência. $\mathrm{O}$ presente artigo mostrase útil por trazer à discussão acadêmica a temática dos efeitos das atividades extracurriculares no desenvolvimento infantil e adolescente. Dessa forma, quando se pensar em políticas públicas para crianças e adolescentes fora do âmbito escolar, poder-se-á contar com apontamentos de estudos que destacam a real necessi- dade destas ações, para além das implicações sociais em relação ao público participante.

\section{O que dizem algumas pesquisas empíricas sobre as atividades extracurriculares}

Como mencionado anteriormente, existem efeitos significativos das atividades extracurriculares oferecidas a crianças e adolescentes. Um ponto comum nas investigações descritas na presente oportunidade é o foco do objeto de pesquisa nas ações para além da escola, que podem interagir em diversos aspectos da vida de seus participantes. Alguns estudos relatam achados que vão para além de ações articuladas, por exemplo, aqueles que estudaram os efeitos que o cuidado de um irmão maior pode surtir sobre a criança pequena, tanto na vida da criança-cuidadora (Poletto $\&$ cols., 2004) como daquela que é cuidada (Coley \& cols., 2004).

Posner e Vandell (1999) destacam que as horas após a escola são partes do dia fundamentais para o desenvolvimento das crianças e adolescentes. Estes autores realizaram uma investigação com crianças de baixa renda, que teve como intuito examinar a utilização do tempo fora da escola quando as crianças estavam na terceira e quarta séries do ensino fundamental. Os autores investigaram também a relação entre as atividades realizadas com o ajustamento social, acadêmico e emocional das crianças. A fím de evitar dificuldades conceituais, Posner e Vandell (1999) adotaram algumas definições para as análises. Assim, atividades acadêmicas referem-se a fazer o dever de casa e ler; e as atividades não estruturadas fora de casa seriam esportes praticados de maneira informal. Dentro de casa os autores identificaram as atividades de jogar videogames, participar de atividades organizadas no computador ou jogos de tabuleiro, como o xadrez. Já as atividades extracurriculares não esportivas incluem participar de cursos enriquecedores como música, dança, atividades de grupos organizados fora de casa como escoteiros ou encontros com grupos especiais (Posner \& Vandell, 1999).

Para comparar as informações das atividades extracurriculares com outras variáveis, Posner e Vandell (1999) pesquisaram o desempenho acadêmico na escola onde os sujeitos estudavam. Os professores e os pais foram convidados a avaliar o comportamento das crianças mediante o preenchimento de escalas que abordavam aspectos relacionados a atitudes das crianças em determinadas situações. Dentre os principais resultados de Posner e Vandell (1999), observa-se que as meninas utilizaram mais tempo realizando atividades acadêmicas e de socialização do que os meninos. 
Porém, os garotos gastam mais tempo com esportes organizados. Foi notado também que os sujeitos que participam de programas extracurriculares realizam mais atividades diferentes, e não somente esportes. Estas crianças também assistem menos televisão, fazem poucas atividades não estruturadas e gastam menos tempo em atividades de trabalho. Elas utilizam seu tempo em atividades acadêmicas, jogos de tabuleiro e esportes orientados (Posner \& Vandell, 1999).

Os principais resultados do estudo de Posner e Vandell (1999) mostram que a atividade com maior incidência, realizada no período da tarde após a escola, é assistir televisão (20\%). As outras atividades frequentes foram estar no trânsito - percurso da escola para casa - (15\%) e acadêmicas $(14 \%)$. As crianças deste estudo, de uma maneira geral, utilizam quase $10 \%$ de suas tardes pós-escola em atividades fora de casa não estruturadas (Posner \& Vandell, 1999). Os dados apontaram ainda que as crianças que gastavam menos tempo em atividades extracurriculares correspondiam a $4 \%$, em trabalhos - apesar dos autores não especificarem que tipo de trabalho estes sujeitos realizavam, possivelmente tratava-se de atividades do lar, como arrumar a casa e cuidar de irmãos - $(4 \%)$ e esportes estruturados (4\%). Os dados de Posner e Vandell (1999) apontam, de uma maneira geral, que sujeitos com melhor ajustamento emocional são aqueles que participam de programas extracurriculares. Estes eram estruturados e possuíam uma organização própria e as atividades eram executadas após a escola. Eles ofereciam ajuda no dever de casa, atividades recreativas, como basquete e futebol, três ou mais vezes por semana, no final do período escolar (Posner \& Vandell, 1994).

Cooper e cols., (1999) encontraram resultados semelhantes aos de Posner e Vandell (1994; 1999) em um estudo cujo principal objetivo foi investigar a relação entre atividades após a escola e o desempenho acadêmico de adolescentes. Estes estudiosos analisaram cinco tipos de atividades extracurriculares: dever de casa, assistir televisão, trabalho, participação em clubes acadêmicos e/ou de esportes, e outras que dizem respeito a atividades em grupos estruturados (como escoteiros e grupos ligados à igreja). A fim de verificar o desempenho acadêmico dos adolescentes, Cooper e cols. (1999) relacionaram os dados coletados com os resultados de um programa de avaliação, administrado pelo estado norte-americano do Tennessee (Tennessee Comprehensive Assessment Program - TCAP). O TCAP avaliou o vocabulário, compreensão de leitura, expressão da linguagem, fala, compreensão matemática, cálculos matemáticos, ciências, estu- dos sociais e habilidades de estudo. Os principais resultados encontrados nesta pesquisa foram que a participação em atividades extracurriculares em grupos estruturados se relacionaram positivamente com os resultados das variáveis avaliadas pelo TCAP. Porém, o mesmo não aconteceu na comparação entre atividades relacionadas a trabalho e assistir televisão. Os autores comprovaram a hipótese de que fazer o dever de casa e participar de atividades extracurriculares organizadas pode indicar um prognóstico positivo de desempenho acadêmico. Corroborando a conclusão das investigações de Posner e Vandell (1999) e de Cooper e cols. (1999), que assistir menos televisão pode contribuir, em certa medida, para um melhor desempenho em atividades escolares.

Pode-se perceber que há diversos estudos em que as atividades extracurriculares são apontadas como importantes para o desenvolvimento de crianças, adolescentes e até mesmo de jovens adultos (Cooper \& cols., 1999; Mahoney \& cols., 2006; Posner \& Vandell, 1994/ 1999). Alguns dados chamam atenção para o impacto das experiências em programas após a escola em crianças já no início da idade escolar.

Pierce, Hamm e Vandell (1999) estudaram programas que realizam atividades após a escola para crianças da primeira série e examinaram a associação entre a experiência destes sujeitos com sua adaptação na escola. Os programas examinados possuem características similares às de salas de aula, como um número elevado de crianças, cuidadores com a função de professores, e possibilidades de interações com colegas em atividades de grupo e individual. Os pesquisadores observaram que não foi possível determinar se as experiências das crianças após a escola afetam o seu desempenho na escola. No entanto, os achados de Pierce e cols. (1999) demonstram que as crianças obtêm benefícios de atividades pós-escola realizadas em ambientes positivos, isto é, que propiciam interações saudáveis. Estes beneficiados podem melhorar seu desempenho na interação social com colegas, assim como em habilidades sociais que podem refletir em seus comportamentos em outros contextos para além da escola.

É possível observar que os apontamentos feitos por Pierce e cols. (1999) corroboram os achados dos estudos realizados por Posner e Vandell (1994; 1999), por Cooper e cols. (1999) e por Mahoney e cols. (2006). Verifica-se que o impacto das atividades extracurriculares para o desenvolvimento integral da criança e do adolescente é extremamente relevante. Dessa forma, visualiza-se que os resultados das ações após a escola podem ir ainda mais além. 
Mahoney (2000) realizou um estudo longitudinal, que teve como principal objetivo examinar a relação entre a participação de crianças e adolescentes em atividades extracurriculares e o padrão de comportamento antissocial da infância até a juventude. A amostra foi entrevistada quando tinha aproximadamente 10 anos, 13 anos e novamente quando estava nas idades de 20 e de 24 anos. As atividades extracurriculares identificadas na investigação de Mahoney (2000) foram divididas nos seguintes grupos: atléticas (baseball, basquete, futebol), assistenciais (servir mesas nas refeições, assistente de biblioteca), artes (clube de arte, coral, teatro), e acadêmicas (clube de História, Francês e negócios) (Mahoney \& Cairns, 1997). Os estudos de Mahoney e sua equipe mostram que a participação em atividades extracurriculares promove uma oportunidade para criar uma conexão positiva e voluntária com a instituição escolar (Mahoney, 2000; Mahoney \& Cairns, 1997). Talvez o dado mais relevante seja o de que a participação nas atividades extracurriculares continua a ter uma influência positiva ao longo dos anos escolares. Finalmente, Mahoney aponta que o envolvimento em atividades extracurriculares pode estar associado com reduzidas taxas de abandono escolar e de criminalidade entre meninos e meninas que vivem sob elevado risco de desenvolvimento. Além disso, demonstra que há uma abertura para a mudança no desenvolvimento na adolescência e não somente na infância (Mahoney, 2000).

\section{CONSIDERAÇÕES FINAIS}

É possível afirmar, a partir de estudos realizados por diversos pesquisadores, que as atividades extracurriculares exercem uma influência significativa no desenvolvimento de crianças e adolescentes. Portanto, informações apontam a necessidade de o Estado investir em Políticas Públicas em prol do público infantil e adolescente, além da escola formal. Ou então que a escola de tempo integral seja efetivada, não através de atividades dentro de salas com quadros e carteiras, mas sim com atividades diferenciadas.

Os dados disponíveis no Brasil, sobre o que as crianças fazem após ou antes da escola, apontam que este público usa o seu tempo livre para assistir TV/vídeos/DVDs em casa como brincadeira (Carneiro \& Dodge, 2007). Pode-se estimar que, com exceção de estudantes de escolas de tempo integral, as crianças e adolescentes têm aproximadamente 8 horas de tempo livre, fora da escola, para realizar tarefas como: fazer o para casa, brincar ou participar de atividades variadas - aulas de música, atividades esportivas, escolas de línguas, entre outras. Ou seja, é provável que crianças e adolescentes, no Brasil, utilizam este tempo em atividades não estruturadas e de lazer. Saber o impacto destas ações no desenvolvimento deste público pode ser útil para a implantação de políticas públicas tanto de proteção social como de Educação.

Os dados de Carneiro \& Dodge (2007) já apontam questões importantes sobre o panorama brasileiro em relação ao brincar. As autoras destacam que "um brincar de qualidade" (grifo das autoras) (p. 243) pode contribuir para as crianças no desenvolvimento de habilidades mais adequadas no que tange à cooperação, tornando-as mais alegres, tranquilas, extrovertidas, autônomas e curiosas. No entanto, faz-se necessário, também, o levantamento de dados sobre ações para além do brincar, desenvolvidas em atividades estruturadas, tais como escolas de esporte, aulas de músicas, recreativas, entre outras, ligadas a projetos sociais, por exemplo.

Não resta dúvida quanto à importância do brincar e da necessidade de inclusão do mesmo no contexto educacional. Carneiro e Dodge (2007) destacam este fato com extrema pertinência. É preciso destacar que o intuito deste estudo vai além desta questão e isto justifica o fato do não aprofundamento sobre o tema do brincar propriamente dito. Além disso, estudiosos têm sugerido que o período de lazer ou de atividades livres poderia ser melhor utilizado de outras maneiras, como a participação em programas de alta qualidade, após ou antes da hora de ir para a escola. Isto pode facilitar o desenvolvimento positivo e prevenir a emergência de problemas do desenvolvimento (Eccles $\&$ cols., 2003). Portanto, constata-se que é de extrema necessidade a realização de estudos brasileiros que possam apontar os efeitos que as atividades extracurriculares ou ações socioeducativas apresentam para os seus participantes no Brasil. Sobretudo, ao se ter em mente que os dados encontrados em outros países podem não ser detectados no contexto brasileiro. No entanto, os resultados de outros estudos servem de subsídios para se pensar em pesquisas aplicadas. Nestas investigações, é imprescindível o desenvolvimento de instrumentos para se buscar dados que possam apontar os impactos das ações para além da escola, como questionários, inventários, escalas, testes, dentre outros - ou até mesmo a padronização, para o contexto brasileiro, do material utilizado em pesquisas realizadas por Posner e Vandell (1999), Mahoney (2000), entre outros.

Por todas as informações destacadas, vê-se que as atividades extracurriculares influenciam positivamente o desenvolvimento de crianças e adolescentes. 
Com isto, é de extrema relevância que estas ações tenham planejamento e sejam orientadas, para que haja uma conjugação profícua da ação de proteção e educação integral. Para que isto aconteça, de forma efetiva, é preciso que as políticas públicas, nesta área, sejam garantidas em lei e que deixem o caráter de prerrogativa de governos específicos. Pois, assim, pode-se manter uma ação contínua destas atividades, que abarque a todos e não a segmentos específicos da sociedade. Ou então, que a escola em tempo integral e o aumento da jornada escolar sejam realidades, deixando de estar presentes apenas na Lei de Diretrizes e Bases da Educação de 1996.

Enfim, observa-se que as atividades para além da escola resultam em impactos positivos no desenvolvimento de crianças e adolescentes. A elaboração e execução de políticas públicas, com este intuito, devem ter um planejamento estruturado. Ou seja, estas ações devem ser espaços de aprendizagens enriquecidas, que fomentem a possibilidade de crianças e adolescentes construírem conhecimentos e habilidades que impulsionem o sucesso e a sua permanência na escola formal, provocando efeitos significativos nas avaliações educacionais a que os alunos brasileiros se submetem.

\section{REFERÊNCIAS}

Obs.: Referências precedidas de um asterisco indicam estudos incluídos na revisão.

Brasil. (1996). Lei n. 9.394, de 20 de dezembro de 1996. Lei de Diretrizes e Bases da Educação Nacional. Brasília, DF.

* Carneiro, M. A. B., \& Dodge, J. J. (2007). A descoberta do brincar. São Paulo: Melhoramentos/Boa Companhia.

* Carvalho, M. C. B., \& Azevedo, M. J. (2005). Ações socioeducativas no âmbito das políticas públicas. Em Centro de Estudos e Pesquisas em Educação, Cultura e Ação Comunitária CENPEC (Org.), Avaliação: Construindo parâmetros das ações socioeducativas (pp. 25-33). São Paulo: CENPEC/Fundação Itaú Social/UNICEF.

* Centro de Estudos e Pesquisas em Educação, Cultura e Ação Comunitária - CENPEC (2002). Guia de ações complementares à escola para crianças e adolescentes ( $3^{\mathrm{a}}$ ed.). São Paulo: CENPEC/UNICEF.

* Centro de Estudos e Pesquisas em Educação, Cultura e Ação Comunitária - CENPEC (2003). Muitos lugares para aprender. São Paulo: CENPEC/Fundação Itaú Social/UNICEF.

Circo de Todo Mundo (2004). Em busca da infância perdida: A experiência de erradicação do trabalho infantil doméstico em Belo Horizonte. Brasília: OIT.

* Coley, R. L., Morris, J. E., \& Hernandez D. (2004). Out-ofschool care and problem behavior trajectories among low- income adolescents: Individual, family, and neighborhood characteristics as added risks. Child Development, 75(3), 948-965.

* Cooper, H., Valentine, J. C., Nye, B., \& Lindsay, J. J. (1999). Relationships between five after-school activities and academic achievement. Journal of Educational Psychology, 91(2), 369-378.

* Eccles, J. S., \& Taempleton, J. (2002). Extracurricular and other after-school activities for youth. Review of Educational Research, 26, 113-180.

* Eccles, J. S., Stone, M., \& Hunt, J. (2003). Extracurricular activities and adolescent development. Journal of Social Issues, 59, 10-43.

* Ferreira, E. A. P., \& Mettel, T. P. L. (1999). Interação ente irmãos em situação de cuidados formais. Psicologia: Reflexão e Crítica, 12(1), 133-146.

Guará, I. M. F. R. (2003). Educação, proteção social e muitos espaços para aprender. Em Centro de Estudos e Pesquisas em Educação, Cultura e Ação Comunitária - CENPEC (Org.), Muitos lugares para aprender (pp. 31-45). São Paulo. CENPEC/Fundação Itaú Social/Unicef.

Guará, I. M. F. R. (2007). Educação Integral: Articulação de projetos e espaços de aprendizagem. Retirado em 06 de maio de 2007, de http://www.cenpec.org.br/modules/xt_conteudo/ index.php?id=46

* Hansen, D., Larson, R., \& Dworkin, J. (2003). What adolescents learn in organized youth activities: A survey of self-reported developmental experiences. Journal of Research on Adolescence, 13, 25-26.

* Huston, A. C. (2005). Connecting the science of child development to public policy. Social Policy Report, 19, 1-20.

* Huston, A. C., Wright, J. C., Marquis, J., \& Green, S. B. (1999). How young children spend their time: Television and other activities. Developmental Psychology, 35(4), 912-925.

Instituto da Criança e do Adolescente (Org.) (2006). Educador talvez seja isso mesmo... Belo Horizonte: PUC/MG.

* Mahoney, J. L., Harris, A. L., \& Eccles J. S. (2006). Organized activity participation, positive youth development, and the over-scheduling hypothesis. Social Policy Report, 20, 1-32.

* Mahoney, J. L., \& Caims, R. B. (1997). Do extracurricular activities protect against early school dropout? Developmental Psychology, 32, 241-253.

* Mahoney, J. L. (2000). Participation in school extracurricular activities as moderator in the development of antisocial patterns. Child Development, 71, 502-516.

* Mahoney, J. L., Caims, B. D., \& Farmer, T. (2003). Promoting interpersonal competence and educational success trough extracurricular activity participation. Journal of Educational Psychology, 95, 409-418.

* Mahoney, J. L., Lord, H., \& Carryl, E. (2005). An ecological analysis of after-school program participation and the development of academic performance and motivational attributes for disadvantaged children. Child Development, 76, 811-825.

Matias, N. C. F., \& Souza, L. K. de (2007a). A importância de programas extracurriculares para o desenvolvimento infantil e adolescente [Resumo]. Em M. S. B. Goulart (Org.), I Colóquio Interinstitucional de Laboratórios de Psicologia (pp. 68-69). Belo Horizonte: PUC-MG. 
Matias, N. C. F., \& Souza, L. K. (2007b). A produção científica internacional em atividades extracurriculares para crianças $e$ adolescentes [Resumo]. Trabalho apresentado no XVI Encontro Brasileiro de Psicoterapia e Medicina Comportamental. Resumo retirado em 15 de novembro de 2007, de http://www. abpmc.org.br/anais.asp

Matias, N. F. C. (2007). Políticas públicas para além da escola: Um levantamento bibliográfico sobre atividades extracurriculares. Monografia de especialização não- publicada, Universidade Federal de Minas Gerais.

Matias, N. C. F. (2009). Escolas de tempo integral e atividades extracurriculares: Universos à espera da psicologia brasileira. Psicologia em Revista, 15(3), 120-139.

Matias, N. C. F. (2008). Contribuições das atividades extracurriculares para a escola em tempo integral. Manuscrito submetido à publicação.

* Mchale, S. M., Crouter, A. C., \& Tucker, C. J. (2001). Free-time activities in middle childhood: Links with adjustment in early adolescence. Child Development, 72(6), 1764-1778.

* National Institute OF Child Health and Human Development Early Child Care Research Network (2004). Are child developmental outcomes related to before- and after-school care arrangements? Results from the NICHD study of early child care. Child Development, 75(1), 280-295.

* Pierce, K. M., Hamm, J. V., \& Vandell, D. L. (1999). Experiences in after-school programs and children's adjustment in firstgrade classrooms. Child Development, 70(3), 756-767.
* Poletto, M., Wagner, T. M., \& Koller, S. H. (2004). Resiliência e desenvolvimento infantil de crianças que cuidam de crianças: Uma visão em perspectiva. Psicologia: Teoria e Pesquisa, 20(3), 241-250.

* Posner, J. K., \& Vandell, D. L. (1994). Low-income children's after-school care: Are there beneficial effects of after-school programs? Child Development, 65, 440-456.

* Posner, J. K., \& Vandell, D. L. (1999). After-school activities and the development of low-income urban children: A longitudinal study. Development Psychology, 35, 868-879.

* Sherrod, L. (2006). From the editor. Social Policy Report, 20, 2.

Siman, A. M. (2005). Políticas públicas: A implementação como objeto de reflexão teórica e como desafio prático. Tese de doutorado não-publicada, Universidade Federal de Minas Gerais.

Souza, C. (2003). Políticas públicas e orçamento público: Conflitos e cooperação. Em M. V. Benevides, P. Vannuchi \& F. Kerche (Orgs.), Reforma política e cidadania (pp. 134-161). São Paulo: Fundação Perseu Abramo.

Zauli, E. M. (2003). Políticas públicas e políticas sociais. Pensar BH-Política Social, 8, 27-29.

\section{Notas:}

1 Este trabalho foi redigido com base na literatura utilizada na introdução da monografia "Políticas Públicas para Além da Escola: Um Levantamento Bibliográfico sobre Atividades Extracurriculares", apresentada ao curso de Especialização em Políticas Públicas do Departamento de Ciência Política da Faculdade de Filosofia e Ciências Humanas da Universidade Federal de Minas Gerais. A partir dos dados do levantamento inicial, para a elaboração de outro artigo, foram acrescentadas informações sobre escolas de tempo integral, até o ano de 2008, restritas a três periódicos: Psicologia: Teoria e Pesquisa, Psicologia: Reflexão e Crítica e Psicologia Escolar e Educacional (Matias, 2009). Estes dados são relacionados ao contexto brasileiro. Em Matias (2008) encontram-se informações relacionadas à publicações de trabalhos vinculados a periódicos internacionais.

2 Não há uma tradução direta desta palavra para a língua portuguesa. Policymakers corresponde a pessoas que planejam a política, que a constroem na esfera governamental.

3 A realização desta análise encontra-se em artigo submetido à publicação (Matias, 2008).

\section{Sobre o autor:}

Neyfsom Carlos Fernandes Matias: Psicólogo pela Pontifícia Universidade Católica de Minas Gerais, Especialista em Políticas Públicas e Mestrando em Psicologia da Universidade Federal de Minas Gerais. Atua como supervisor técnico de Organizações Não Governamentais, conveniadas com a Prefeitura Municipal de Belo Horizonte através da Secretaria Municipal Adjunta de Assistência Social / Gerência de Proteção Social Básica / Programa de Socialização Infanto-Juvenil.

Endereço para correspondência: Rua: Francisco Bicalho, 1112 - Bairro Padre Eustáquio - 30720-340 Belo Horizonte - MG. Endereço eletrônico: neyfsom@yahoo.com.br. 